\title{
Membrane technology costs and me
}

S. J. Judd, Gas Processing Center, Qatar University, Cranfield Water Science Institute, Canfield University

Email: simon.judd@qu.edu.qa

\section{Abstract}

A reflection of the place cost analysis holds in membrane process technology research and development is provided. The review encompassed two membrane processes and applications: (a) Reverse osmosis (RO) for seawater desalination, and (b) membrane bioreactor (MBR) technology for wastewater treatment. The cost analysis undertaken extended to (i) the determination of operating expenditure (OPEX) trends using simple analytical expressions, (ii) the subsequent estimation of the sensitivity of OPEX to individual system parameters, and (iii) published data on CAPEX for individual full-scale installations or from cost analyses. An appraisal of the peer-reviewed literature through a survey of a leading scientific database was also carried out. This bibliometric analysis was based on authors' keywords; it aimed to establish the profile of process cost for each of the two applications when compared with other popular related topics.

The OPEX analysis, ostensibly through a consideration of specific energy demand in $\mathrm{kWh}$ per $\mathrm{m}^{3}$ permeate, revealed it to relate primarily to hydrodynamics in the case of $\mathrm{RO}$, and to both membrane fouling and air scouring for MBRs. The bibliometric analysis of research trends revealed a marked difference in emphasis on cost aspects between the two research areas, with the focus on cost specifically being 16 times greater for RO desalination of seawater than MBR treatment of wastewater. MBR research appears to be dominated by fouling and foulant characterisation, making up almost a quarter of all studies, notwithstanding evidence from practitioners that other process parameters are as important in determining MBR process OPEX and operability.

Keywords: reverse osmosis; membrane bioreactor; seawater desalination; wastewater treatment; fouling; cost analysis.

\section{Introduction}

Membrane technology for water treatment extends back to the mid-19th Century, with the earliest pioneering work owing much to the German nation. Wilibald Schmidt (1856) published what must count as the first ultrafiltration (UF) separation study based on a bovine heart-based membrane. By the early $20^{\text {th }}$ century Heinrich Bechhold (1907) had started testing synthetic UF membranes, and even came up with the name "ultrafilter". The commercial development, by Sartorius Werke Gmbh, of microfiltration (MF) membranes followed in the mid-1920s, following the earlier studies of Richard Zsigmondy and Willhelm Bachman (Zsigmondy and Bachman, 1918). Reverse osmosis (RO) membranes capable of desalinating seawater were originally developed by US researchers in the 1950s, but it was then left to Sydney Loeb and Srinivasa Sourirajan (Loeb and Sourirajan, 1964), working at Ottawa in the early 1960s, to patent an asymmetric RO membrane with a sufficiently thin selective membrane layer to yield a reasonable flux. A host of commercial advancements and refinements in fabrication methods and manufacturing generally since this time have seen significant falls in production costs and increases in product quality across all membrane types. 
It could thus be said that membrane technology is at least half a century old; even the key hybrid membrane bioreactor (MBR) technology is very nearly this age, the original process having developed in the late 1960s by Dorr Oliver (Bemberis et al, 1971). Notwithstanding this, there remains some resistance - regional, cultural or otherwise - to implementation of membrane technology for some duties or in certain circumstances in the municipal water sector. This arises despite compound annual growth rate (CAGR) values 10-23\% quoted for RO desalination and MBR technology by market survey companies such as BCC (Runte, 2016), MarketsandMarkets (2014), and Frost and Sullivan (2013), compared to generally single-digit values for conventional water and wastewater treatment equipment.

In some ways the reluctance to select membrane technology can be justified. There remain operational issues with some membrane processes and/or specific applications which are yet to be comprehensively addressed. Operation and maintenance $(\mathrm{O} \& \mathrm{M})$ of any membrane process tends to be more complex than alternative classical processes because of the vigilance required in keeping the surface of the membranes clean and the channels between them clear. Ultimately, though, the choice between classical and membrane technology - as with almost anything else - comes down to money.

Costs, regardless of how they're determined, can all be categorised as either capitalinvestment cost or operating/running cost. For a full-scale membrane installation the operating expenditure (OPEX) is predominantly determined by the energy and chemical demand, critical component replacement (namely the membrane), water supply and wastewater discharge charges, and other items such as labour and servicing. Capital expenditure (CAPEX) is normally taken to include all equipment, installation services such as civil engineering, mechanical and electrical (M\&E) and consultancy, and land costs. CAPEX and OPEX can be combined to produce the net present value (NPV), which accounts for the cost of financing by assuming that investment of the capital sum elsewhere will produce an annual return quantified by the discount rate.

It is of obvious interest to consider the extent to which the costs of implementing and operating membrane process plants in water and wastewater treatment have been or are likely to be impacted by scientific, technological and commercial developments. This review considers the two commercially significant municipal membrane separation technologies of reverse osmosis for seawater desalination and membrane bioreactors for wastewater treatment. Apart from the significant market growth, these processes represent the two most important with respect to their application. More than 50\% of drinking water generated through desalination of seawater and brackish water is via RO, equating to a global market value of more than $£ 10 \mathrm{~b}$ (Runte, 2016). MBR technology provides the highest attainable performance for a biological process in terms of biochemical efficacy and treated wastewater quality with reference to clarity and microorganism content.

\section{$2 \quad$ Trends in costs}

As with most water and wastewater treatment challenges or applications, there are technical options. For desalination, the alternative to RO is thermal evaporation, normally multiple-stage flash or multiple effect distillation (MSF and MED respectively). For wastewater treatment there are many technological alternatives to MBRs but the process is most often benchmarked against the classical activated sludge process (CAS). The very rapid growth in implementation of both MBR and RO technology is principally due to the commensurate relative decrease in cost of both these technologies compared to that of the alternative. 
In general, capital costs are reported infrequently and, very often, inconsistently, incompletely and/or without itemisation. It is not always evident as to whether highly-locational and site specific data, such as land and legal/contractual costs, have been included and, if so, their quantitative contribution. Also, the delineation of costs between civil and material costs can differ between reports, as can the identification of critical component replacement; for membrane plants, the membrane itself contributes to both the CAPEX and the OPEX, the latter being related to the membrane life and permeate flux. OPEX, on the other hand, can be estimated from a consideration of the individual contributions, these comprising energy, chemicals usage, labour and servicing costs (including the supply and discharge of water), critical component replacement and other miscellaneous items.

For both RO technology for desalination and MBR technology for wastewater treatment, the decline in OPEX since original implementation has been primarily through improved energy efficiency. The energy demand (or consumption) has received by far the most attention of all of the contributions to OPEX. It has been the key basis of comparison between RO and MSF technologies (Karagiannis and Soldatos, 2008) and for MBR vs. CAS (Young et al, 2013, 2014; Wosniak, 2012; Foley et al, 2010). Energy demand has also formed the focus of studies of hybrid technologies such as MSF/RO (Hamed, 2016; Shahzad et al, 2016) and MBR-forward osmosis (Chen et al, 2014), as well as regional reviews of MBR installations (Iglesias et al, 2017; Xiao et al, 2014). The energy demand derives largely from (i) the pumping of water (for all processes, but especially for RO), (ii) heating (for evaporative processes), and (iii) the pumping of air (for suspended growth biological processes such as MBR and CAS technologies).

\subsection{RO vs thermal desalination}

A number of cost analyses have been published since the implementation of RO for seawater desalination in the late 1970s (Al-Gholaikah et al, 1978). Up until this point seawater deslaination was through evaporation, the thermal energy demand for the process being largely mitigated through its combination with power generation to access the waste steam from the latter process. For both RO and MSF the technological costs have declined considerably since their early implementation. For example, the cost of MSF for seawater desalination has been calculated to have declined from around $\$ 9 \mathrm{~m}^{-3}$ in the late 1950 's to almost one tenth this cost in 2000 (Zhou and Tol, 2004), albeit with considerable data scatter. The same authors determined a decline from $\$ 4.5$ to $\sim \$ 1.5 \mathrm{~m}^{-3}$ for RO for the same application between 1977 and 2000. The basis for the decline in OPEX can best be appreciated through a consideration of energy demand.

\subsubsection{Energy demand}

The specific energy demand (SED, or $E$ ) can be estimated from governing expressions with respect to the primary energy source for MSF and RO respectively (Rautenbach and Albrecht, 1989):

$$
\begin{aligned}
& E_{M S F}=c_{L}\left(\frac{1}{N}+\frac{\Delta T_{T}}{\Delta T_{o}}\right)\left(1-\xi_{\text {steam }}\right)+E_{e l} \xi_{p p} \\
& E_{R O} \xi_{p p}=\frac{\Delta P_{R O}+\Delta P_{\text {loss }}+\Delta \pi C F}{\rho\left(1-\frac{1}{C F}\right) \xi_{\text {pump }}}+\frac{\left(\Delta P_{R O}+\Delta \pi C F\right) \xi_{\text {turb }}}{\rho(C F-1)}+E_{\text {el }}
\end{aligned}
$$

where: 
$\mathrm{c}_{\mathrm{L}} \quad$ Latent heat of evaporation, $\mathrm{kWh} \mathrm{m}^{-3}(85)$

$C F \quad$ Concentration factor $C_{\text {brine }} / C_{\text {feed }} \sim(1-\theta)^{-1}$, where $\theta$ is the conversion, $Q_{\text {permeate }} / Q_{\text {feed }}$

$E_{E l} \quad$ Electrical power consumption $\mathrm{kWh} \mathrm{m}^{-3}(0.16)$

$\Delta p_{R O} \quad$ RO "pure water" operational pressure (1.4)

$\Delta p_{\text {loss }} \quad$ Pressure losses across retentate side (1.6)

$\mathrm{N} \quad$ No. of MSF stages

$\Delta T_{T} \quad$ Total temperature change due to heat losses (4.2)

$\Delta T_{o} \quad$ Flash range of brine, $\mathrm{T}_{\mathrm{B}, \max }-\mathrm{T}_{\mathrm{B}, \min }$

$\xi_{\text {steam }}$ Efficiency of waste steam provision

$\xi_{\text {turb }}$ Efficiency of energy recovery turbine $(95 \%)$

$\xi_{p p} \quad$ Power plant efficiency $(40 \%)$

$\xi_{\text {pump }} \quad$ Pumping energy efficiency $(65 \%)$

$\rho \quad$ Product water density, $\mathrm{kg} \mathrm{m}^{-3}(1000)$

$\Delta \pi \quad$ Osmotic pressure difference, $\mathrm{kPa}, \sim \mathrm{TDS}(\mathrm{mg} / \mathrm{L}) / 15$

- (base values for analysis)

The efficiency terms in Equations 1-2 are of key importance in determining E. In Equation 1, $\xi_{\text {steam }}$ represents the proportion of the thermal energy required (to sustain the process) which is provided by the waste steam from the power plant. If the steam can be harnessed at $100 \%$ efficiency the first term in Equation 1 disappears, such that heat losses in the thermal process become immaterial. Both Equations 1 and 2 account for the key difference in energy source between the two technologies (heat and electrical) through assigning an efficiency $\xi_{p p}$ for power production. The $\xi_{\text {turb }}$ term in the RO equation refers to the efficiency of the energy recovery turbine, most usually a Pelton wheel, employed on the brine (or retentate) discharge stream. Finally, the pumps also have a finite efficiency converting electrical to mechanical energy.

The above relationships indicate that $E$ is sensitive to different parameters for the different technologies. In the case of MSF it is mainly the flash range and the number of stages which impact on energy efficiency (Fig. 1): there is no influence of salt concentration. For RO there is a significant impact of the feed salt concentration (Fig. 2), and also of the conversion $\theta$ (the ratio of the permeate to the feed flow rate), which impact on both the osmotic pressure and the flow and pressure of the waste brine to the recovery turbine. The energy recovery provided by the latter means that there is an energy minimum at a CF normally somewhere between 1.45 and 1.85 (or $\sim 30-45 \%$ permeate recovery), depending on the feed salt concentration.

There are fundamentally important outcomes from the SED determination. Taking a baseline salt concentration of $4 \mathrm{wt} \%$ and assuming reasonable base values of all operating parameters, the impact of a $10 \%$ change in salt concentration, energy recovery efficiency, pressure loss along the retentate channel and pure water membrane permeability can be estimated (Table 1). This indicates salt concentration to have by far most significant impact on SED and, at the membrane surface, is directly affected by concentration polarisation (CP). $\mathrm{CP}$ is a mass transfer/hydrodynamic phenomenon, influenced more by fluid mechanics than by membrane properties, especially given the narrow operating envelope of membrane flux imposed by osmotic pressure of the feedwater. There is therefore less to be gained from developing innately high-permeability membranes, such as carbon nanotubes (Kim et al, 2016), than from optimising system hydrodynamics: it is in the engineering of the membrane module, to improve hydrodynamics and suppress CP, where energy efficiency gains may arise - although there is a case for improving RO membrane selectivity (Werber et al, 2016). 


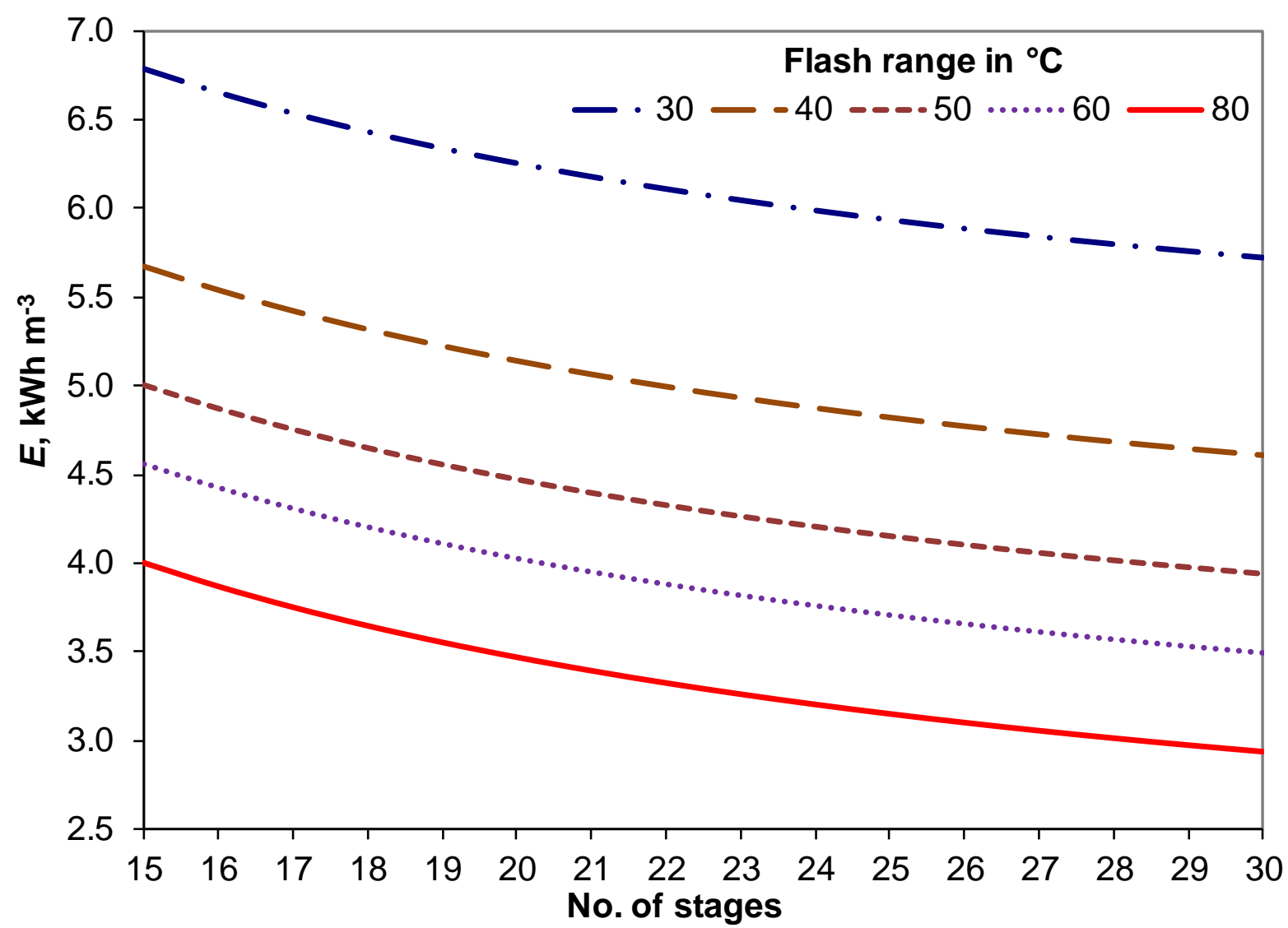

Figure 1: $\quad$ Specific energy demand vs. number of stages at different flash ranges for an MSF

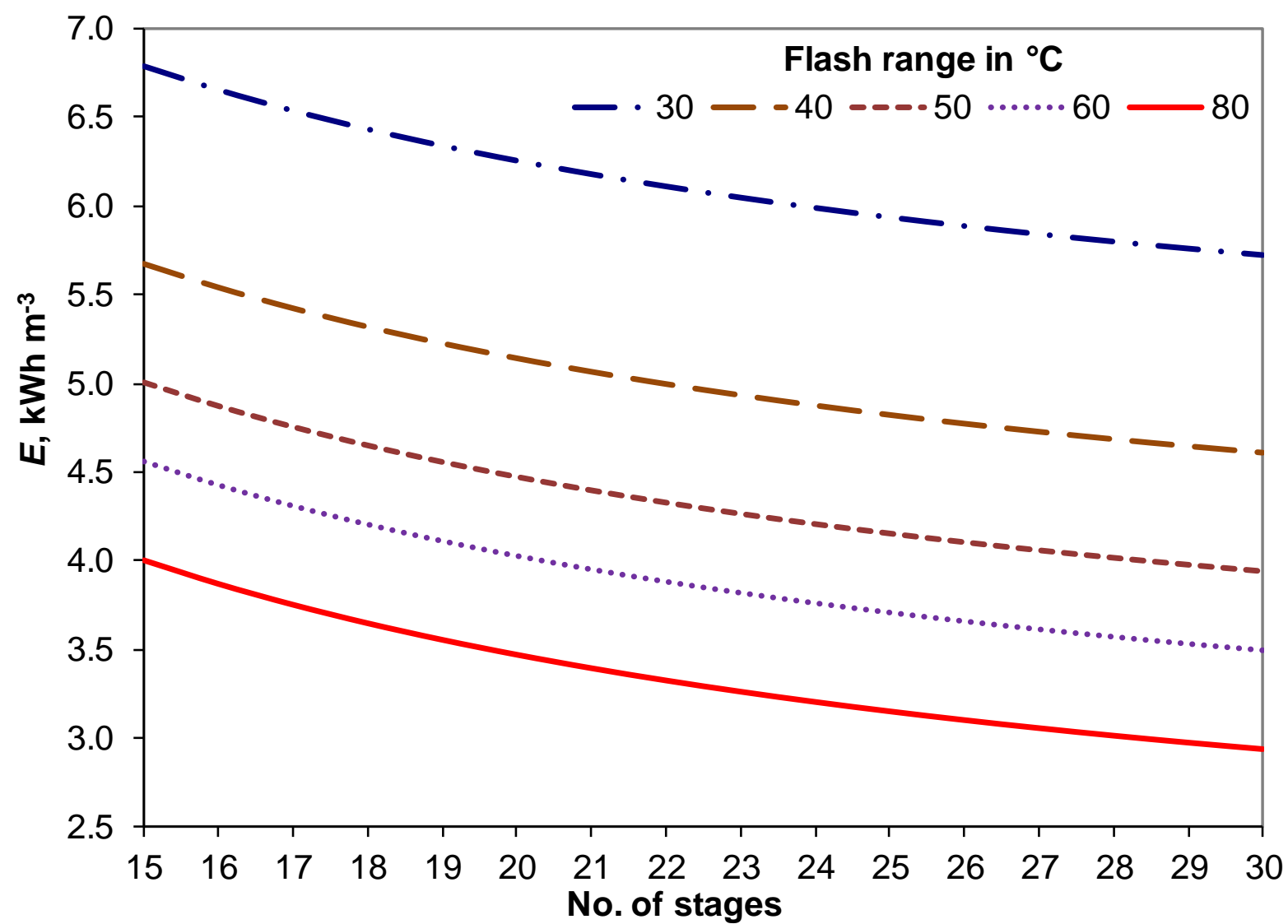

Figure 2: $\quad$ Specific energy demand vs. brine concentration factor at different feed salt concentrations 
Table 1. Impact of key parameters on specific energy demand, RO

\begin{tabular}{l|c}
\hline Parameter change & Change in $\boldsymbol{E}$ \\
\hline $10 \%$ reduction in salt concentration (4 to $3.6 \mathrm{wt} \%)$ & $\mathbf{7 . 8 \%}$ \\
$10 \%$ relative increase in energy recovery $(80$ to $88 \%)$ & $\mathbf{3 . 5 \%}$ \\
$10 \%$ decrease in pressure losses (1.6 to 1.44 bar $\Delta p$ loss $)$ & $\mathbf{0 . 4 \%}$ \\
$10 \%$ decrease in membrane permeability $\left(1.5\right.$ to 1.35 bar $\left.\Delta p_{R O}\right)$ & $\mathbf{0 . 2 \%}$ \\
\hline
\end{tabular}

\subsubsection{Other OPEX contributors}

Whilst energy normally represents the principal OPEX component in RO seawater desalination installations - more than 50\%, combined chemicals consumption and membrane replacement can contribute between 15 and $25 \%$ of the total cost depending on the feedwater quality, operating conditions and membrane life (Gude, 2016). A membrane life of 5-7 years is normally assumed (Jamil et al, 2017; Voutchkov, 2013; Park et al, 2010), although it has been suggested that applying more frequent and aggressive chemical cleaning to allow a membrane life of 10 years can be more cost effective (Ruiz-García and Ruiz-Saavedra, 2015). Determination of membrane life impacts are common to both RO and MBR technologies (Section 2.2.2).

\subsubsection{CAPEX}

As previously stated, CAPEX is highly location specific, and particularly susceptible to extensive civil engineering work and/or extended pipelines. In some cases costs have been mitigated through contracting or related financial arrangements, with BOO/T schemes (Build, Own and Operate/Transfer) being shown to be particularly effective in reducing costs (Voutchkov, 2013). Available CAPEX data (Table 2) suggests that a significant range of costs per unit flow capacity exists (from $\$ 0.52$ to 2.3 per MLD, or megalitre per day), but this is largely attributed to the site circumstances. Examples of the latter include the possibility of shared facilities, extent of water conveyancing and civil engineering work.

Table 2. RO desalination plants

\begin{tabular}{l|ccccccc}
\hline Name & Ashkelon & Tuas & Perth & Sydney & Sorek & Wilf et al, 2008 \\
\hline Year & 2005 & 2005 & 2006 & 2009 & 2013 & & \\
Location & Israel & Singapore & Australia & Australia & Israel & - & - \\
Capacity, MLD & 330 & 110 & 144 & 250 & 624 & 38 & 385 \\
SED, $\mathrm{kWh} / \mathrm{m}^{3}$ & 4 & 4.1 & 3.5 & 4.9 & 3.7 & - & - \\
CAPEX, \$m & 212 & 200 & 281 & 1539 & 400 & - & - \\
\$m/MLD & 0.64 & 1.82 & 1.95 & 6.16 & 0.64 & $1.69^{*}$ & $1.77^{*}$ \\
Tarif, $\$ / \mathrm{m}^{3}$ & 0.52 & 0.48 & 0.87 & 2.29 & 0.58 & - & - \\
\hline
\end{tabular}

MLD megalitres per day; *average figures.

\subsubsection{Outlook}

Whilst the thermal evaporation combination plants are still viable in countries where energy costs are low - primarily in the Arabian Gulf region - the overall costs for the thermal process in real terms have changed little since the turn of the millennium and are currently in the region of $\$ 0.8-1.1 \mathrm{~m}^{-3}$, based on large combination plants (Gude, 2016). Against this, the current cost for the equivalent $\mathrm{RO}$ technology is around $\$ 0.5 \mathrm{~m}^{-3}$, having declined roughly in line with improved energy efficiencies of $20-30 \%$ in the past 15 years (Sanz, 2012). This appears to have been achieved through a combination of improved RO membrane and technology design and increased energy recovery from the high-pressure retentate stream. The latter contributes significantly to energy savings. Whereas the $1990 \mathrm{RO}$ plant at Jeddah was not fitted with energy recovery and had an SED of $8.1 \mathrm{kWh} / \mathrm{m}^{3}$, subsequent energy-optimised plants have reported energy demands less than half of this value (Table 2). These incremental improvements have 
meant that, whereas in 2005 the ratio of thermal to membrane-generated desalinated water volumes was $\sim 60: 40$, the ratio is currently nearer 35:65 (Gude, 2016).

Further gains in energy efficiency have most recently focused largely on renewable energy sources. In the case of thermal processes viable sources of energy include solar and geothermal (Ghaffour et al, 2015; Chandrashekara and Yadav, 2017) since the thermal energy can be harnessed directly. For the RO technology energy conversion, normally via Rankine cycles, is required for such thermal sources (Bruno et al, 2008; Salcedo et al, 2012). The most widely explored renewable energy options for this option have been through the use of photovoltaic (PV) cells and wind turbines (WT) (Peñate and García-Rodríguez, 2012), the latter having been implemented used to offset coal-powered electricity at the Perth desalination plant. Whilst renewable energy sources offset non-renewable energy demand, the overall impact of renewable energy implementation on costs has been observed to be detrimental due to the high PV and WT equipment costs (Karagiannis and Soldatos, 2008). Notwithstanding this, sustainability considerations are driving the implementation of renewables technologies for desalination generally, whether thermal (using solar or geothermal sources) or membrane-based (including membrane distillation).

\subsection{MBR vs. CAS technologies}

Recent comparative MBR cost analyses, most notably the comprehensive work of Young et al (2013, 2014) based on an immersed hollow fibre (iHF) membrane, have demonstrated overall cost benefits of MBR over CAS technology despite the higher OPEX for the MBR. These authors demonstrated, through determination of the NPV to account for all costs over the full life of the installation, that the MBR offered an overall cost benefit through the substantially reduced CAPEX for circumstances where land costs were high and enhanced nutrient removal was required. As with RO, significant reduction in costs over the early years of implementation of the technology have been reported, with membrane whole life costs decreasing from $\$ 400 / \mathrm{m}^{2}$ in 1992 to below $\$ 50 / \mathrm{m}^{2}$ in 2005 for the original immersed flat sheet (iFS) technology (Kennedy and Churchouse, 2005). Corresponding order-of-magnitude decreases in energy demand have been demonstrated for the market leading $\mathrm{HHF}$ product since its introduction introduced in the mid-1990s (Ginzberg, 2013).

\subsubsection{Energy demand}

In the case of the CAS and MBR the SED derives mainly from aeration, for providing air to the biomass and, in the case of the MBR, scouring the membrane (Judd, 2014):

$$
\begin{aligned}
& E_{C A S}=E_{A, b i o} S A D_{\text {bio }}+E_{\text {sludge }} \sum R+E_{\text {el }} \\
& E_{M B R}=E_{A, m}^{\prime} S A D_{p}+E_{A, b i o}^{\prime} S A D_{\text {bio }}+E_{\text {sludge }} \sum R+E_{L, m}+E_{\text {el }}
\end{aligned}
$$

where:

$E_{A, m}{ }_{A, m}$ Specific energy demand per unit air volume, membrane tank, $\mathrm{kWh} \mathrm{Nm}^{-3}(0.022)$

$E^{\prime}{ }_{A, \text { bio }}$ Specific energy demand per unit air volume, process tank, $\mathrm{kWh} \mathrm{Nm}^{-3}$ (23)

$E_{\text {sludge }}$ Specific energy demand, sludge pumping (power/flow), $\mathrm{kWh} \mathrm{m}^{-3}(0.018)$

$E_{L, m} \quad$ Specific energy demand, permeate pumping (power/flow), $\mathrm{kWh} \mathrm{m}^{-3}(0.015)$

$E_{e l} \quad$ Specific residual electrical power consumption, $\mathrm{kWh} \mathrm{m}^{-3}(0.005)$

$\sum R \quad$ Sum of recycle ratios (5)

$S A D_{p} \quad$ Specific aeration demand for membrane scouring, air per unit permeate volume, $\mathrm{Nm}^{3}$ $\mathrm{m}^{-3}(0.25)$ 
$S A D_{\text {bio }}$ Specific aeration demand for biological process, air per unit permeate volume, $\mathrm{Nm}^{3}$ $\mathrm{m}^{-3}$

(base values for analysis)

The two aeration energy parameters of $E_{A, m}^{\prime}$ and $E_{A, b i o}{ }^{\prime}$, in kWh of energy per temperaturenormalised cubic metre $\left(\mathrm{Nm}^{3}\right)$ of air, differ slightly according to the depth of the aerator in the tank. However, they are normally in the range of $0.016-0.025 \mathrm{kWh} \mathrm{Nm}^{-3}$ with the higher end of the range applying to process aeration where the tanks are usually deeper. The corresponding aeration demands $\left(S A D_{b i o}\right.$ and $S A D_{p}$ in $\mathrm{Nm}^{3}$ air per $\mathrm{m}^{3}$ permeate water delivered, for process and membrane aeration respectively), on the other hand, are a function of two different parameters. $S A D_{b i o}$ increases with the organic load and the oxygen transfer efficiency, the latter being lower for the CAS than for the MBR due to the impact of the higher solids concentration in the process tank. $S A D_{p}$ is determined by the shear and/or mixing demanded at the membrane surface: it is the ratio of the air scour rate per unit membrane area $\left(S A D_{m}\right.$ in $\mathrm{Nm}^{3} \mathrm{~h}^{-1}$ per m $\left.\mathrm{m}^{2}\right)$ and the flux $J$ (in $\left.\mathrm{m} \mathrm{h}^{-1}\right)$. Much of the commercial membrane development over the past 15 years has focused on maximising the mixing imparted by membrane air scouring while minimising the amount of air required for this, resulting in significant improvements in energy efficiency which is to some extent mitigated by overly conservative $S A D_{m}$ values warranteed by some technology suppliers. There is nonetheless always a greater energy demand for the MBR, albeit below $0.5 \mathrm{kWh} \mathrm{m}^{-3}$ for large, optimised plants according to some surveys (Krzeminski et al, 2017; Iglesian et al, 2017; Itokawa et al, 2014; Xiao et al, 2014), than for the CAS because of the additional aeration and permeate pumping requirements.

\subsubsection{Other OPEX contributors}

As with RO (Section 2.1.2), other OPEX components, ignoring site-specific elements like servicing and labour, comprise chemicals usage and membrane replacement. The membrane replacement component of the OPEX is proportional to the ratio of the membrane cost $\left(L_{m}\right)$ to the net flux $(J)$ times the membrane life $(t)$ : OPEX $\propto L /(J t)$. Overall OPEX thus decreases with increasing flux and membrane life (Fig. 3), provided there is no deleterious impact on operation in the form of increased cleaning frequency and other unscheduled extensive manual interventions. Whilst MBRs are always more expensive to operate than the equivalent CAS system, some of these costs may be offset by the reduced plant footprint, reduced sludge volumes and the value added by the higher treated water quality.

Whilst membrane replacement is still considered to provide the most significant contribution to OPEX after energy, iHF membrane costs appear to have reached levels of $\$ 15-25 \mathrm{~m}^{-2}$ - similar to those of RO membranes (Pearce, 2010). This has arisen despite the significant challenge of non-standardisation in the MBR market: unlike RO elements, which are a standard size and spiral-wound configuration, MBR membrane modules are not completely interchangeable. Against this, it is unclear as to how much further the traditional rigid panel polymeric iFS membranes can decrease in cost, the cost having fallen by an order of magnitude from the price range $\sim \$ 400-500 \mathrm{~m}^{-2}$ of the early 1990's (Kennedy and Churchouse, 2005).

As with RO desalination, the sensitivity of OPEX to specific parameters can be determined using the base parameter values to which the trends depicted in Figure 3 refer. Accordingly, it is apparent that increasing the flux has the greatest impact on OPEX (Table 3), since it impacts both on specific energy demand and membrane replacement costs. However, given that the fouling rate is widely observed as being exponentially related to the applied flux ( $\mathrm{Li}$ et al, 2013; Guglielmi et al, 2007), increasing the flux by $20 \%$ is a substantially greater challenge than decreasing the air scouring. The efficacy of reduced aeration was demonstrated commercially 
by GE when they introduced intermittent coarse bubble aeration, decreasing $S A D_{m}$ initially by $50 \%$ ("10:10 aeration") and then subsequently by a further $50 \%$ ("10:30 aeration") for their ZW500 module, with no apparent detriment to the flux. The company has subsequently achieved a further 20-30\% reduction is $S A D_{m}$ with its latest design (Ginzburg, 2013). As with RO desalination, the impact of MBR membrane permeability on energy demand is negligible at $0.3 \%$ (Table 3 ), the same as the value for RO for a similar \% permeability change.

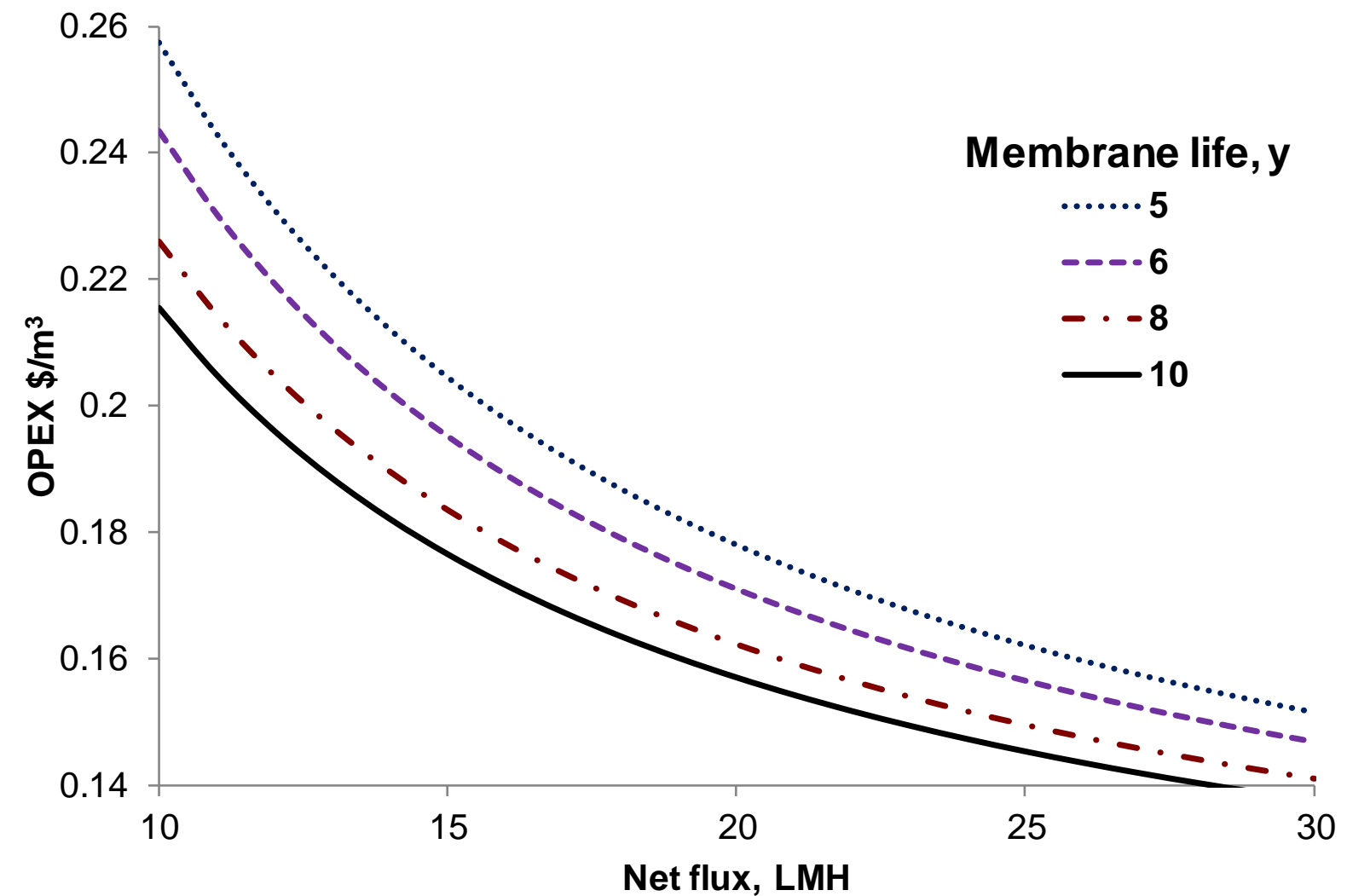

Figure 3: MBR OPEX vs flux as a function of membrane life. $S A D_{m}=0.25 \mathrm{Nm}^{3} \mathrm{~m}^{-2} ; E_{L, m}=0.015 \mathrm{kWh} \mathrm{m}^{-3}$; $L_{m}=\$ 25 \mathrm{~m}^{-2} ; L_{e}=\$ 0.12 \mathrm{kWh}^{-1} ; \sum R=5 ; E_{A, m}^{\prime}=0.022 \mathrm{kWh} \mathrm{Nm}^{-3} ; E_{\text {sludge }}=0.018 ; E_{A, b i o}^{\prime} S A D_{\text {bio }}=$ $0.5 \mathrm{kWh} \mathrm{m}^{-3}$.

Table 3. Impact of key parameters on specific energy demand, MBR

\begin{tabular}{l|c}
\hline Table 4. Parameter change & Change in $\boldsymbol{E}$ \\
\hline $20 \%$ increase in flux (20 to 24 LMH) & $-6.5 \%$ \\
$20 \%$ decrease in $S A D_{m}\left(0.25\right.$ to $\left.0.2 \mathrm{Nm}^{3} \mathrm{~m}^{-2}\right)$ & $-5.0 \%$ \\
$20 \%$ increase in membrane life $(8$ to 9.6 years $)$ & $-2.3 \%$ \\
$20 \%$ decrease in membrane permeability $\left(E_{L, m} 0.015\right.$ to $\left.0.012 \mathrm{kWh} \mathrm{m}^{-3}\right)$ & $-0.3 \%$ \\
\hline
\end{tabular}

\subsubsection{CAPEX}

A recent review of costs (Lo et al, 2015), using cost analysis data from full-scale installations, suggests CAPEX values for a 20 MLD capacity MBR plant of $\$ 0.35-\$ 0.68 \mathrm{~m}$ (2015 USD) per MLD (Young et al, 2013, 2014; Verrecht et al, 2010; De Carolis et al, 2007). As such the numbers appear to be somewhat lower than those associated with RO desalination (Table 2), although, as with desalination, the CAPEX can increase considerably depending on circumstances. Young et al (2013) determined a CAPEX of up to $\$ 2.6 \mathrm{~m} / \mathrm{MLD}$ when including downstream UV disinfection and primary settling. Municipal MBRs operate at only a slightly higher net flux than RO desalination plants but employ membranes which tend to be higher in 
cost per unit area. MBR plants also incur a larger footprint than RO installations due to the biological tank, which demands a hydraulic residence time of at least 6 hours. The apparently lower CAPEX is thus perhaps counter-intuitive, but perhaps reflects differences in required equipment and construction materials for seawater desalination.

\subsubsection{Outlook}

As with RO membranes, there are probably only minor incremental improvements in cost efficiencies attainable from the classical membrane separation process, i.e. immersed MBRs with membrane air scouring of polymeric membranes. Decreased membrane aeration always increases the risk of membrane fouling and/or channel clogging (Zsirai et al, 2014): the intervention required to mitigate clogging in particular is more punitive economically and practically than the energy cost savings offered by aeration reduction.

However, the emergence of the new FS ceramic membranes, with a predicted life at least double that of the polymeric membranes and with a purportedly higher operating flux (Niwa et al, 2016), may change the paradigm of MBR membrane selection. Since the membrane replacement component of the OPEX relates to $L m /(J t)$ (Section 2.2.2), the cost effectiveness of a novel candidate membrane compared with the conventional one is simply determined by the ratio of $L_{m} /(J t)$ for the two materials. For example, if a ceramic material costs four times as much but lasts twice as long and operates at double the flux (or half the $S A D_{p}$ ) of the polymeric material then there is parity of the OPEX between the two. Whilst ceramic membranes are currently considered too costly to be viable, there good reason to suppose that this will change. The Metawater multichannel monolith product has full-scale potable water references dating back 10 years and the current cost of the material appears to be in the $\$ 80-160$ per $\mathrm{m}^{2}$ range. Whilst this may still be uncompetitive, it seems reasonable to assume that costs will continue to fall from the $>1000 \$ / \mathrm{m}^{2}$ level of a $\sim 10$ years ago (Benko et al, 2008) in a manner analogous to that of polymeric iFS membranes 15-25 years ago (Kennedy and Churchouse, 2005).

\section{Trends in membrane technology research}

An indication of the relative importance of the different areas of study can be obtained from reviewing the authors' keywords and/or title taken from peer-reviewed papers listed in research publication databases. Whilst this approach does not capture all publications pertaining to the subject areas of interest, the approach has been employed (Santos et al, 2011; Judd et al 2015) to elucidate historical trends and the relative profile of specific topics. The use of keywords provides an insight into the key topics of the published study as perceived by the authors, since it is they who select the keywords regarded as being most pertinent to the publication.

\subsection{Bibliometric analytical method}

The analysis was based on the author keywords of publications appearing in the SCOPUS database, and the search terms and combinations thereof indicated in Table 3. The period analysed was 2001-2016, divided biennially. The downloaded keywords were converted to a text file and the most common words identified and their incidences individually summed using the TextStat programme. The values were then manually checked using the Ctrl-f function in MS Excel applying the appropriate term or word root (Table 4), allowing visual identification of the set of keywords for each publication. Terms or words of key interest were then analysed further and then, if appropriate, grouped to provide the sum total pertaining to a specific topic. The numbers obtained were then normalised against the total number of incidences from the top 20 keywords/terms to give an incidence percentage $I$ : 


$$
I, \%=\frac{n_{i}}{\sum_{n=1}^{n=20} n_{i}}
$$

where $n_{i}=$ number of incidences of keywords, keyword roots, or keyword sets $i$ within a given (biennial, in this case) time period.

Visual checking of the set of keywords for each entry ensured that no duplication of terms took place; for example, if extracellular polymeric substances and EPS were both mentioned in the same set of keywords for a single paper only one of the incidences was counted.

Table 5. Bibliometric analytical terms/roots used

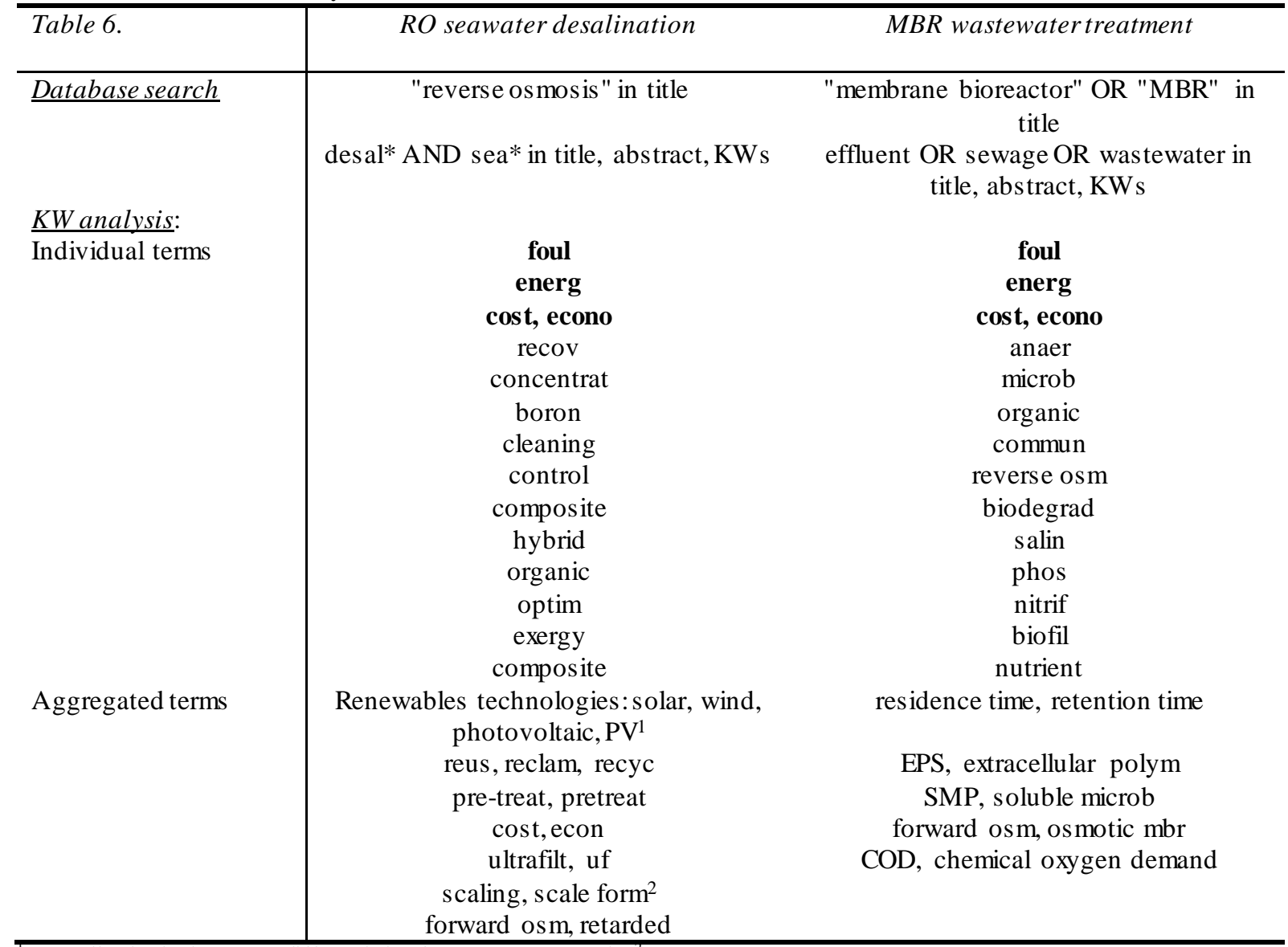

Tanually checked to ensure differentiation from "pressure vessel"; ${ }^{2}$ Manually checked to ensure differentiation from scale of operation

\subsection{Bibliometric results}

Results of the bibliometric analysis for RO desalination of seawater (Fig. 4) and MBR treatment of wastewater (Fig. 5) suggest a number of trends:

- Membrane fouling features strongly in both areas, and particularly so for MBR treatment of wastewater where the $I$ value is between 20 and 31\% from the 2003-04 biennial period onwards;

- For RO around $45 \%$ of the incidences of fouling refer to biofouling;

- Pre-treatment, particularly be ultrafiltration, also features strongly and consistently from year to year in RO desalination studies;

- Cost and, in particular energy, feature more strongly in studies of RO desalination of seawater than in MBR wastewater treatment studies; 
- The subject of energy in RO publications is, in part, manifested as renewable energy sources, such as solar and wind power;

- Whilst energy demand does not appear to be the primary focus of MBR studies:

○ specific energy demand is inversely related to flux (Section 2.2.2), which decreases with increasing fouling, and

o research into the key low-energy technology of anaerobic MBRs has steadily increased, with the $I$ value increasing almost four-fold in the past 16 years;

- There is evidently increased research activity in forward osmosis (FO) for seawater desalination, $I$ increasing from zero to $11 \%$ between 2007-08 and 2015-16. Similarly, over the same period the $I$ value for topics in FO within the MBR space have increased from zero to $3.6 \%$.

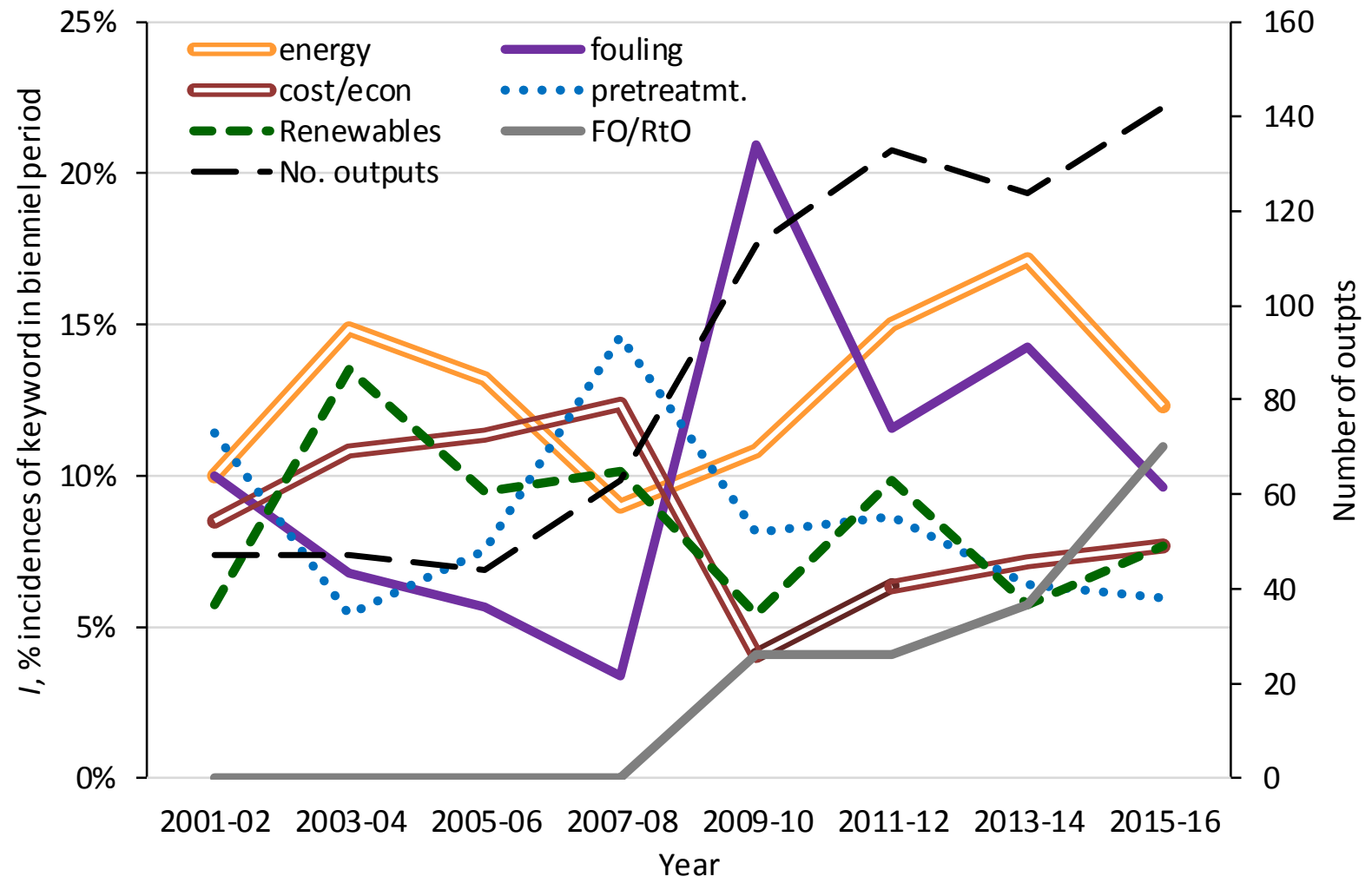

Figure 4: I values relating to RO desalination of seawater, SCOPUS keywords analysis; the "renewables" category is based specifically on the terms solar, wind, and photovoltaic or PV (see Table 3)

Whilst providing illuminating trends, care should be taken in employing and interpreting these and other bibliometric data. It is not possible to capture all relevant papers through this method, such that only relative trends between the different selected topics can be elucidated with any confidence. It is also critically important that the changes in terminology (e.g. reuse vs. reclamation) are encompassed in the search and all ambiguities resolved (e.g. PV = "photovoltaic" or "pressure vessel"). These caveats aside, it is apparent that costing has a considerably higher profile in RO desalination research than for MBR technology: a manual inspection of the outputs reveals that the vast majority of the publications featuring the keyword terms "cost" or "econo" are based on economic assessments. 


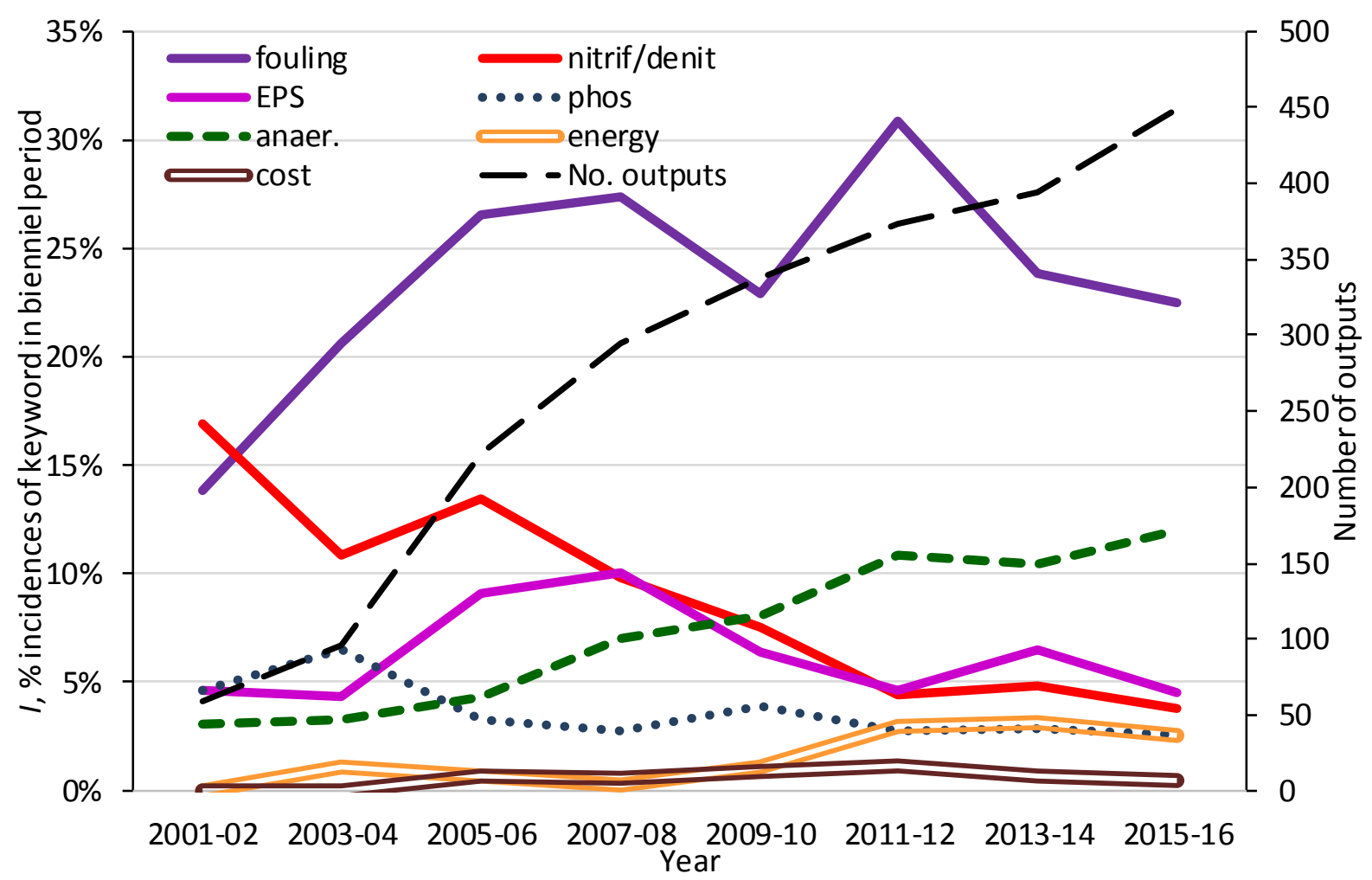

Figure 5: $\quad I$ values relating to RO desalination of seawater, SCOPUS keywords analysis

\section{$4 \quad$ Impact of research on practical cost reduction}

Membrane technology research has historically tended to focus on membrane fouling. Fouling is normally taken to encompass all phenomena which cause a decrease in the membrane permeability due to deposition onto or into the membrane. For RO processes fouling also negatively impacts on perm-selectivity (Penña et al, 2013), and is generally complex because it includes organic and inorganic (scale) surface fouling as well as internal pore plugging by colloidal materials. It is also recognised that key types of fouling, and biological fouling specifically, present a continuing challenge to the process (Warsinger et al, 2015) and demand a solution which may arise from a concerted research effort. The focus on biofouling in RO seawater desalination research would therefore seem appropriate given the scale of the challenge in practice.

In the case of MBRs a disproportionate amount of research appears to have been dedicated to the study of MBR fouling ( $I=24 \%$ on average over the period considered) and its characterisation, especially in comparison to RO seawater desalination for which $I=10 \%$ for fouling studies. The emphasis on characterisation is evidenced by the preponderance of the term EPS (extracellular polymeric substances) with an $I$ value of $4-10 \%$ for each biennial period (Fig. 5). Notwithstanding this large body of research, all practical evidence from full-scale operation suggests that surface fouling is predominantly successfully mitigated by chemical cleaning with a combination of hypochlorite and citric acid (Wang et al, 2014; Judd, 2010; Brepols et al, 2008). Whilst fouling impacts directly on cost (Table 3), it is by no means the only parameter doing so and is not necessarily the most logical system facet to target given that it is determined by the microbiology which, by its nature, is not readily controlled. 
Most crucially, there is a marked difference in emphasis on cost between the two research areas. Whilst cost sensitivity seems to be considered a valid subject for research in desalination technology, and perhaps other water/wastewater treatment areas (such as algal technologies), this does not seem to be the case for MBRs. This is reflected in the respective $I$ values: cost determination/analysis-based publications in the RO seawater desalination space provide an average $I$ factor of more than $8 \%$ over the period considered, compared to a corresponding value for papers encompassing costs in the MBR wastewater treatment space of $\sim 0.5 \%$. Moreover, anecdotal evidence from surveys (Judd, 2016) suggests that issues such as membrane channel clogging, energy demand and, for some sites, foaming feature as prominently as membrane fouling amongst the concerns of MBR practitioner community (in addition to cost). There is no evidence of the incremental improvements in cost effectiveness achieved over the past 25 years being in directly attributable to the considerable scientific research effort in fouling and its characterisation. In practice, the improved energy efficiencies and decreased membrane costs that have combined to make MBRs more cost competitive appear to have arisen from innovations in engineering design and manufacturing respectively.

There is thus a common thread in membrane technology development when considering those aspects which ultimately determine cost-effectiveness. Whilst much research has been conducted on the science of the two processes and applications considered here, the reality is that actual practical developments that have led to cost reductions owe more to engineering. This dislocation between the research and practitioner communities is hardly a new observation, but is particularly apparent in MBR research where the focus on practically relevant aspects has been less apparent than in the case of RO seawater desalination. Although there have been a few studies which have directly addressed quantified energy efficiency improvement, such as aeration optimisation at full scale for the process (Sun et al, 2016) and membrane scour (Monclús et al, 2015), such investigations have been vastly outnumbered by fouling studies. There would thus appear to be a strong case for reflection on what is fundamentally important. And that, of course, is money.

\section{Acknowledgements}

This work was made possible by the support of a National Priorities Research Programme (NPRP) grant from the Qatar National Research Fund (QNRF), grant reference number NPRP8 1115-2-473. The statements made herein are solely the responsibility of the author.

\section{References}

Al-Gholaikah, A., El-Ramly, N., Jamjoom, I., and Seaton, R. (1978). The world's first large seawater reverse osmosis desalination plant, at Jeddah, Kingdom of Saudi Arabia. Desalination, 27(3), 215-231.

Bechhold, H. (1907). Kolloidstudien mit der Filtrationsmethode Z. Physik Chem., 13(32), 527-533.

Bemberis, I., Hubbard, P. J., Leonard, F. B. (1971) Membrane sewage treatment systems - potentialfor complete wastewater treatment, Amer. Soc. Agric. Eng. Winter Mtg., 71-878, 1-28.

Benko, K., Drewes, J., Xu, P., and Cath, T. (2008). Use of ceramic membranes for produced water treatment, 15th Annual International Petroleum \& Biofuels Environmental Conference, November 10-13, Albuquerque, NM.

Brepols, C., Drensla, K., Janot, A., Trimborn, M., and Engelhardt, N. (2008). Strategies for chemical cleaning in large scale membrane bioreactors. Water Sci. Technol., 57(3) 457-463.

Bruno, J. C., López-Villada, J., Letelier, E., Romera, S., and Coronas, A. (2008). Modelling and optimis ation of solar organic rankine cycle engines for reverse osmosis desalination. Appl. Therm. Enging., 28(17-18), 2212-2226. 
Chandrashekara, M., C., and Yadav, A. (2017). Water desalination system using solar heat: A review. Renew. Sustain. En. Rev., 67, 1308-1330.

Chen, L., Gu, Y., Cao, C., Zhang, J., Ng, J. -., and Tang, C. (2014). Performance of a submerged anaerobic membrane bioreactor with forward osmosis membrane for low-strength wastewater treatment. Water Res., 50, 114-123.

DeCarolis, J., Adham, S., Pearce, W.R., Hirani, Z., Lacy, S., Stephenson, R., (2007). Cost trends of MBR systems for municipal wastewater treatment, Proc. Water Env. Fed., 13-17 October, San Diego, 3407-3418.

Foley J, de Haas D, Hartley K, and Lant P. (2010). Comprehensive life cycle inventories of alternative wastewater treatment systems. Water Res. 44, 1654-1666.

Frost and Sullivan (2013). Global Membrane Bioreactor (MBR) Market, Research Code M7E2-01-00-00-00, Jan 2013.

Ghaffour, N., Bundschuh, J., Mahmoudi, H., and Goosen, M. F. A. (2015). Renewable energy-driven desalination technologies: A comprehensive review on challenges and potential applications of integrated systems. Desalination, 356, 94-114.

Ginzburg, B. (2013). LEAPmbr Process Design. MEA UFMBR Workshop for ITPs, 4-7 November, Abu Dhabi.

Gude, V. G. (2016). Desalination and sustainability - an apprais al and current perspective. Water Res., 89, 87-106.

Guglielmi, G., Saroj, D. P., Chiarani, D., and Andreottola, G. (2007). Sub-critical fouling in a membrane bioreactor for municipal wastewater treatment: Experimental investigation and mathematical modelling. Water Res., 41(17), 3903-3914.

Hamed, O. A. (2016). Thermoeconomic analysis of combined power cycle integrated with MSF/SWRO desalination plant. Desal. Water Treat., 57(55), 26552-26561.

Iglesias, R., Simón, P., Moragas, L., Arce, A., Rodriguez-Roda, I. (2017). Comparison of full scale water reclamation technologies with an emphasis on membrane bioreactors. Water Sci. Technol., in press.

Itokawa, H., Tsuji, K., Yamashita, K., and Hashimoto, T. (2014). Design and operating experiences of full-scale municipal membrane bioreactors in Japan. Water Sci. Technol., 69(5), 1088-1093.

Jamil, M. A., Qureshi, B. A., and Zubair, S. M. (2017). Exergo-economic analysis of a seawater reverse osmosis desalination plant with various retrofit options. Desalination, 401, 88-98.

Judd, S. (2010). The MBR Book, Butterworth-Heinemann, Oxford.

Judd, S. (2014). Industrial MBRs, Judd \& Judd, Cranfield (UK).

Judd, S.J. (2016). The status of industrial and municipal effluent treatment with membrane bioreactor technology, Chem. Eng. Jour. 305 37-45.

Judd, S.J., van den Broeke, L.J.P., Shurair, M., Kuti, Y., and Znad, H. (2015). Algal remediation of $\mathrm{CO}_{2}$ and nutrient discharges: a review. Water Res. 87 356-366.

Karagiannis, I. C., and Soldatos, P. G. (2008). Water desalination cost literature: Review and assessment. Desalination, 223(1-3), 448-456.

Kennedy, S., and Churchouse, S. (2005). Progress in membrane bioreactors: new advances, Water and Wastewa ter Europe Conference, June 28-30, Milan.

Kim, Y. M., Ebro, H., anf Kim, J. H. (2016). Molecular dynamics simulation of seawater reverse osmosis desalination using carbon nanotube membranes. Desal. Water Treat., 57(43), 20169-20176.

Krzeminski, P., Leverette, L., Malamis, S., Katsou, E. (2017). Membrane bioreactors - A review on recent developments in energy reduction, fouling control, novel configurations, LCA and market prospects .J. Membrne Sci. 527, 207-227.

Li, J., Zhang, X., Cheng, F., and Liu, Y. (2013). New insights into membrane fouling in submerged MBR under sub-critical flux condition. Biores. Technol., 137, 404-408.

Lo, C.-H., McAdam, E., and Judd, S. (2015). The cost of a small membrane bioreactor, Water Sci. Technol. 72(10) 1739-1746.

Loeb, S., Sourirajan, S. (1964). High flow porous membranes for separating water from saline solutions, US patent 3.133.132. 
MarketsandMarkets (2014). Membrane Bioreactor System Market by Application (Municipal Wastewater Treatment and Industrial Wastewater Treatment), by Type (Hollow Fiber, Flat Sheet, and Multi Tubular), by Configuration (Internal/Submerged and External/ Side stream), and by Region - Trends \& Forecasts to 2019, marketsandmarkets.com, Report Code CH 2651, August 2014.

Monclús, H., Dalmau, M., Gabarrón, S., Ferrero, G., Rodríguez-Roda, I., and Comas, J. (2015). Full-scale validation of an air scour control systemfor energy savings in membrane bioreactors. Water Res., 79, 1-9.

Niwa, T., Matamoto, M., Yamashita, T., Noguchi, Added to reference list: H., Takase, O., Kekre, K.A., Ang, W.S., Tao, G., Seah, H. Yamaguchi, T. (2016). Demonstration of a full-scale plant using an UASB followed by a ceramic MBR for the reclamation of industrial wastewater, Biores. Tech. 218, 1-8.

Park, C., Park, P. -., Mane, P. P., Hyung, H., Gandhi, V., Kim, S. -., and Kim, J. -. (2010). Stochastic cost estimation approach for full-scale reverse osmosis desalination plants. J. Membrane Sci., 364(1-2), 52-64.

Pearce, G. (2010). SWRO pre-treatment: Cost and sustainability. Filt. Sep., 47(2), 36-38.

Peñate, B., and García-Rodríguez, L. (2012). Current trends and future prospects in the design of seawater reverse osmosis desalination technology. Desalination, 284, 1-8.

Penña, N., Gallego, S., del Vigo, F., and Chesters, S. P. (2013). Evaluating impact of fouling on reverse osmosis membranes performance. Desal. Water Treat., 51(4-6), 958-968

Rautenbach, R., and Albrecht, R. (1989). Membrane Processes, Wiley, Lon/NY.

Ruiz-García, A., and Ruiz-Saavedra, E. (2015). 80,000h operational experience and performance analysis of a brackish water reverse osmosis desalination plant. assessment of membrane replacement cost. Desalination, 375, 81-88.

Runte, G. (2016), Seawater and Brackish Water Desalination, BCC, Report Code MST052D, Mar 2016.

Salcedo, R., Antipova, E., Boer, D., Jiménez, L., and Guillén-Gosálbez, G. (2012). Multi-objective optimization of solar rankine cycles coupled with reverse osmosis desalination considering economic and life cycle environmental concerns. Desalination, 286, 358-371.

Santos, A., Ma., W and Judd, S. J. (2011). Membrane bioreactor technology: two decades of research and implementation, Desalination, 273, 148-154.

Sanz, M.A. (2012) Energy as motor of seawater reverse osmosis desalination development, WEX 2012 (The Water and Energy Exchange), 31/1-2/02 2012, Lisbon.

Schmidt, W. (1856). Versuche über Filtrationsgeschwindigkeit verschiedener Flüssigkeiten thierische Membran. Ann. Physik. 175(11) 337-388.

Shahzad, M. W., Thu, K., Ng, K. C., and WonGee, C. (2016). Recent development in thermally activated desalination methods: Achieving an energy efficiency less than $2.5 \mathrm{kWhelec} / \mathrm{m} 3$. Desal. Water Treat., 57(16), 7396-7405.

Sun, J., Liang, P., Yan, X., Zuo, K., Xiao, K., Xia, J., Qiu, Y., Wu, Q., Wu, S., Huang, X., Qi, M., and Wen, X. (2016). Reducing aeration energy consumption in a large-scale membrane bioreactor: Process simulation and engineering application. Water Res., 93, 205-213.

Van Kaam, R., Anne-Archard, D., Alliet, M., Lopez, S., and Albasi, C. (2006). Aeration mode, shear stress and sludge rheology in a submerged membrane bioreactor: Some keys of energy saving. Desalination, 199(1-3), 482484.

Verrecht, B., Nopens, I., Maere, T., Brepols, C., and Judd, S. (2010). The cost of a large-scale hollow fibre MBR, Water Res. 44, 5274-5283.

Voutchkov, N. (2012). Desalination cost trends, from Cost Estimating of SWRO Desalination Plants, MEDRC, June 27, Muscat.

Wang, Z., Ma, J., Tang, C. Y., Kimura, K., Wang, Q., and Han, X. (2014). Membrane cleaning in membrane bioreactors: A review. J. Membrane Sci., 468, 276-307.

Wang,Z., Meng, F., He, X., Zhou, Z., Huang, L., and Liang, S. (2014). Optimisation and performance of NaClO assisted maintenance cleaning for fouling control in membrane bioreactors. Water Res., 53, 1-11.

Warsinger, D. M., Swaminathan, J., Guillen-Burrieza, E., Arafat, H. A., and Lienhard V, J. H. (2015). Scaling and fouling in membrane distillation for desalination applications: A review. Desalination, 356, 294-313. 
Werber, J. R., Deshmukh, A., and Elimelech, M. (2016). The critical need for increased selectivity, not increased water permeability, for desalination membranes. Environ. Sci. Technol. Letts., 3(4), 112-120.

Wilf, M., Awerbuch, L., Bartels, C., Mickley, M., Pearce, G., and Voutchkov, N., (2007). The Guidebook to Membrane Desalination Technology: Reverse Osmosis, Nanofiltration and Hybrid Systems Process Design, Applications and Economics. Balaban Publishers, Rehovot, Israel.

Wozniak, T. (2012). Comparison of a conventional municipal plant, and an MBR plant with and without MPE. Desal. Water Treat., 47(1-3), 341-352.

Xiao, K., Xu, Y., Liang, S., Lei, T., Sun, J.Y., Wen, X.H., Zhang, H.X., Chen, C.S., and Huang, X. 2014. Engineering application of membrane bioreactor for wastewater treatment in China: Current state and future prospect. Front. Env. Sci. Eng., 8(6), 805-819.

Young, T., Smoot, S., Peeters, J., and Côté, P., 2013. When does building an MBR make sense? How variations of local construction and operating cost parameters impact overall project economics, Proc. Water Env. Fed. 8, 6354-6365.

Young, T., Smoot, S., Peeters, J., J., and Côté, P., 2014. Cost-effectiveness of membrane bioreactors treatment systemfor low-level phosphorus reduction from municipal wastewater, Water Practice Technol. 9(3) 316-323.

Zhou Y. and Tol R.S.J. (2004) Implications of desalination to water resources in China - an economic perspective, Desalination, 164 225-240.

Zsigmondy, R., and Bachman, W. (1918). Über neue Filter. Z. Allgem. Chem. 103(1) 119-128.

Zsirai, T., Wang,Z-Z, Gabarrón, S., Connery, K., Fabiyi, M., Larrea, A, and Judd, S.J. (2014), Biological treatment and thickening with a hollow fibre membrane bioreactor, Water Res. 58 29-37. 